\title{
BMJ Open Sleep duration and multimorbidity in Luxembourg: results from the European Health Examination Survey in Luxembourg, 2013-2015
}

Maria Ruiz-Castell, ${ }^{1}$ Tatjana T Makovski, ${ }^{1,2}$ Valéry Bocquet, ${ }^{\circledR 3}$ Saverio Stranges ${ }^{4,5}$

To cite: Ruiz-Castell M, Makovski TT, Bocquet V, et al. Sleep duration and multimorbidity in Luxembourg: results from the European Health Examination Survey in Luxembourg, 2013-2015. BMJ Open 2019;9:e026942. doi:10.1136/ bmjopen-2018-026942

- Prepublication history and additional material for this paper are available online. To view these files, please visit the journal online (http://dx.doi. org/10.1136/bmjopen-2018026942).

Received 28 September 2018 Revised 23 July 2019 Accepted 31 July 2019
Check for updates

(C) Author(s) (or their employer(s)) 2019. Re-use permitted under CC BY-NC. No commercial re-use. See rights and permissions. Published by BMJ.

For numbered affiliations see end of article.

Correspondence to Dr Maria Ruiz-Castell; maria.ruiz@lih.lu

\section{ABSTRACT}

Objectives We estimated the prevalence of short sleep duration and multimorbidity in Luxembourg, and assessed whether sleep duration was associated with multimorbidity after adjusting for sociodemographic and behavioural characteristics.

Design Cross-sectional study.

Participants Data from 1508 Luxembourg residents (48\% men and $52 \%$ women) aged 25 to 64 years came from the European Health Examination Survey 2013-2015.

Outcome measures Short sleep duration and multimorbidity.

Results Participants reported sleeping 6.95hours/night during work days, nearly 1 hour less than during non-work days (7.86 hours/night). Nearly half of participants reported having been diagnosed with $\geq 2$ chronic conditions/ diseases. Short sleep duration was associated with the number of chronic conditions (OR 4.65, 95\% $\mathrm{Cl} 1.48$ to 14.51 ; OR $7.30,95 \% \mathrm{Cl} 2.35$ to 22.58 ; OR $6.79,95 \% \mathrm{Cl}$ 2.15 to 21.41 for 1,2 and $\geq 3$ chronic conditions/diseases, respectively), independently of socioeconomic and behavioural characteristics.

Conclusions Health promotion programmes should aim at improving and promoting healthy lifestyles among the general population to improve sleep habits as well as decrease multimorbidity in middle-aged adults.

\section{INTRODUCTION}

A healthy lifestyle includes healthy sleep habits. Sleep patterns influence several physiological and psychological processes such as inflammation, immune responses, mental and cognitive function, glucose regulation and energy balance. ${ }^{1-3}$ Short sleep duration, poor sleep quality and sleep-related disorders can result in sleep deficiency and impact on individual health. ${ }^{4}$ According to the Centers for Disease Control and Prevention, insufficient sleep is associated with health problems such as chronic diseases, poor quality of life, mental health, risk of accidents and lower productivity at work. ${ }^{5}$ Adequate sleep duration is one of the dimensions needed for good sleep health. ${ }^{6}$ The American Academy of Sleep Medicine and Sleep Research
Strengths and limitations of this study

- This is the first study in Luxembourg on the prevalence of sleep patterns, with a focus on short and long sleep duration, and their relationship with multimorbidity.

- The present study was drawn from the European Health Examination Survey in Luxembourg, a representative cross-sectional population-based survey.

- Limitations of the present study include the subjective self-reported measure of sleep duration, the cross-sectional design of the study (not allowing to establish a causal link) and the low participation rate.

Society consider that for an adult, an average sleep duration of at least 7 hours per night should be recommended. ${ }^{4}$ However, a high percentage of the population sleeps less than the recommended 7 hours. ${ }^{7}$

Several factors may affect sleep such as physical activity patterns or eating behaviours, but also socioeconomic factors including job status, marital status and ethnicity. ${ }^{89}$ Studies have observed an association of lower education and unemployment with both short and long sleep duration, ${ }^{10}{ }^{11}$ while factors such as physical activity and healthy diet seem to improve sleep quality. ${ }^{12}{ }^{13}$ Moreover, diet intake (energy and total fat intake) and nutrients seem to be associated with both short and long sleep duration through multifactorial factors including eating patterns (eg, time and hours of intake) and variations in hormones related to appetite, such as leptin. ${ }^{14}$

Epidemiological data suggest an association of abnormal sleep duration and poor sleep quality with cardiometabolic problems (eg, hypertension, diabetes, obesity, cardiovascular diseases), mental disorders (eg, depression) and mortality. ${ }^{15-18}$ The observed relationship between short sleep duration and mortality would be especially critical in adults 
under 65 years of age.$^{18}$ Few studies so far have focused on possible relationships between sleep patterns and multimorbidity. ${ }^{19}{ }^{20}$ Multimorbidity is defined as the presence of two or more chronic diseases in the same individual, ${ }^{21}$ and is associated with disability, functional decline, frailty, poor quality of life and mortality. ${ }^{22}$ In the context of ageing societies, multimorbidity is an increasing global phenomenon ${ }^{23}$; its occurrence usually increases with age, though a large proportion of individuals younger than 65 are also affected. ${ }^{24}$ Definitions of multimorbidity vary, however, and the prevalence differs based on changing definitions, which in turn present significant challenges when attempting to compare results between populations and studies. ${ }^{22}$

The aim of the present study was to estimate the prevalence of short sleep duration and multimorbidity in Luxembourg, as well as to assess whether sleep duration was associated with multimorbidity after adjusting for sociodemographic and behavioural characteristics.

\section{METHODS}

\section{Study population and recruitment}

Data were drawn from the European Health Examination Survey in Luxembourg (EHES-LUX). EHES-LUX is a representative cross-sectional population-based survey carried out by the Luxembourg Institute of Health with the objectives of assessing the health status of the population of the Grand-Duchy of Luxembourg, develop national and European health indicators, identify the needs of the population and evaluate health behaviours. EHES-LUX was conducted between February 2013 and January 2015. Individuals were randomly selected in a one-stage sampling procedure from the national health insurance registry (95\% social coverage). Institutionalised individuals (eg, hospitals, elderly homes) were not included. A total of 1508 residents (excluding 21 pregnant women) of Luxembourg aged 25 to 64 participated in the survey (participation rate of $24.1 \%$ ). ${ }^{25}$ Of them, seven participants did not report their sleep habits. A total of 1501 participants had information on multimorbidity and sleep habits. Participants were interviewed by trained nurses who also conducted medical examinations. Questionnaires included several health modules (eg, sleep and nutritional habits, healthcare, working and living conditions) as well as demographic and socioeconomic characteristics. Medical examinations included measurements such as blood pressure and anthropometry. Sampling weights were calculated to be generalised to the population of Luxembourg in terms of age, sex and district of residence.

\section{Patient involvement}

Participants were not involved in the development of the research question, study design, recruitment or the conduction of the study. On request, results from the medical examination were forwarded to the study participants and their medical doctors. General results were presented to the general public in a range of dissemination activities.

\section{Sleep}

Sleep duration was assessed using two questions: (1) "How many hours do you normally sleep at night when you have to work the next day?", and (2) "How many hours do you normally sleep at night when you don't have to work the next day?". We calculated a weighted average of sleep duration for each participant by assigning weights of $5 / 7$ to working days and $2 / 7$ to non-working days. ${ }^{26} 27$ Responses were categorised as short sleep duration ( $<6$ hours/ night), medium sleep duration (6-9 hours/night) and long sleep duration ( $>9$ hours/night), in line with previously published studies and sleep time duration recommendations. $^{4828}$

Sleep disorders and sleep quality were assessed with the following variables: difficulty in sleeping the night, diagnosis of sleep disorders, sleep medication and sleepiness. Difficulty in sleeping the night was assessed based on the question "Do you have difficulties in sleeping through the night?". Diagnosis of sleep disorders was assessed using the question "Have you ever been told by a doctor or another health professional that you have a sleep disorder?". Sleep medications were assessed using the question "In the past 2 weeks, have you used other types of medicines that were prescribed to you?". The question was aimed at answering about several medications including sleep tablets. Sleepiness was defined as a score of $\geq 11$ on the Epworth Sleepiness Scale. ${ }^{29}$

\section{Multimorbidity}

Participants were asked if they ever had a chronic disease or condition diagnosed by a medical doctor (eg, hypertension, high cholesterol, diabetes, cardiovascular diseases, stomach or duodenal ulcer, cirrhosis or other liver disease, urinary incontinence, kidney problems, chronic back or neck disorder, rheumatoid arthritis, arthrosis, osteoporosis, cancer, severe headache as migraine or chronic anxiety). Cardiovascular diseases included coronary heart disease or angina pectoris, heart attack or its chronic consequences, stroke or its chronic consequences. Based on this information, the variable 'ever being diagnosed with a chronic disease or condition' was generated with four categories: $0,1,2$ and $\geq 3$ chronic diseases or conditions. Multimorbidity was defined as having two or more chronic diseases or conditions diagnosed by a medical doctor.

\section{Explanatory variables}

Sociodemographic characteristics included age, sex and immigration status. As Portuguese are the largest immigrant community in Luxembourg, immigration status was categorised in non-immigrant, immigrant born in Portugal and immigrant born in other countries. Socioeconomic status included education (primary, secondary and tertiary education completed) and job status 
(unemployed; managers/professionals; technical/clerical/service occupation; skilled/unskilled workers).

Lifestyles included smoking (never; current; ex-smokers), alcohol consumption (never; ex-drinkers; drinkers), physical activity (never; $\leq 3$ hours/week of sports, fitness and/or recreational activities which lasted at least 10 consecutive minutes; $>3$ hours/week of sports, fitness and/or recreational activities which lasted at least 10 consecutive minutes), and vegetable and fruit consumption ( $<1$ portion/day, 1-4 portions/day, $\geq 5$ portions/ day). Weight and height were measured by trained nurses and used to calculate body mass index $\left(\mathrm{BMI} ; \mathrm{kg} / \mathrm{m}^{2}\right)$. BMI was categorised as normal body weight $\left(<25 \mathrm{~kg} / \mathrm{m}^{2}\right)$, overweight $\left(25-29.99 \mathrm{~kg} / \mathrm{m}^{2}\right)$ and obesity $\left(\geq 30 \mathrm{~kg} / \mathrm{m}^{2}\right)$.

\section{Statistical data analysis}

Means and frequencies were used for descriptive purposes. We calculated the prevalence of sleep disorders, short and long sleep duration, chronic conditions/ diseases and multimorbidity. Percentages did not include missing values. A $\chi^{2}$ test or a two-way analysis of variance (ANOVA) were used to analyse associations between the prevalence of sleep duration and covariates and the prevalence of multimorbidity and covariates. The association between sleep duration and chronic conditions/ diseases was assessed using multinomial logistic regression models (reference for sleep duration was 6-9hours per night) adjusted for sociodemographic characteristics, behavioural risk factors (eg, BMI, smoking, alcohol consumption and physical activity), as well as for measures of sleep disorders and sleep quality. We considered a $p$ value $<0.05$ statistically significant. To be representative of the population and avoid biased estimates, the observations were weighted. Participants with missing values on sleep habits and or multimorbidity were not included in the present analysis. Analyses were performed using STATA V.14.0 and and SAS V.9.4 (SAS Institute, Cary, North Carolina, USA).

\section{RESULTS}

Table 1 shows the prevalence of chronic conditions/ diseases, multimorbidity, sleep duration and sleep disorders. Nearly half of participants reported being diagnosed with two or more chronic conditions/diseases, and nearly a third of participants reported being diagnosed with three or more chronic conditions/diseases. The most prevalent diseases were chronic low back disorder or other chronic back defect followed by hypercholesterolemia, arthrosis and hypertension. More than $8 \%$ of participants were diagnosed with a sleep disorder, a third reported having difficulties in sleeping through the night and $4.3 \%$ reported taking sleep medication. Participants reported sleeping 7.86 hours/night when they did not have to work the next day, nearly 1 hour more than when they had to work the next day (6.95 hours/night). Moreover, $5.13 \%$ of the Luxembourg population reported sleeping less than 6 hours/night and $1.79 \%$ reported sleeping more than 9 hours/night.

Participant characteristics by chronic conditions/ diseases are shown in table 2. More men than women presented three or more chronic diseases. Higher number of chronic diseases/conditions increased with age: those aged 55 to 64 presented more chronic conditions compared with those aged 25-34. Immigrants born in Portugal presented more chronic conditions than non-immigrants and other immigrants. Participants being less educated and unemployed presented more chronic conditions compared with those employed and highly educated. Participants being less physically active and with obesity presented more chronic conditions/ diseases than those being more physically active and with a lower BMI.

Participant characteristics by sleep duration are shown in table 3. More men than women reported a medium sleep duration. Short sleep duration was more likely among immigrants born in Portugal, participants with lower education and skilled/unskilled workers. Short sleep duration was less common among those being physically active and with a BMI less than $25 \mathrm{~kg} / \mathrm{m}^{2}$.

Table 4 shows results from multinomial logistic regression analyses examining the association between sleep duration and chronic conditions/diseases, and adjusted by sociodemographic characteristics, behavioural risk factors, socioeconomic position, as well as for measures of sleep disorders and sleep quality. Participants sleeping less hours $(<6$ hours) were 7.30 and 6.79 times as likely to report having two and three or more chronic conditions after adjusting for covariates. In fully adjusted models, the strength of associations between sleep duration and multimorbidity remained statistically significant.

Estimates of sleep problems and chronic conditions are presented in online supplementary table S1. The prevalence of sleep problems was high, with one out of three participants having difficulties in sleeping the night through and nearly $8 \%$ of participants diagnosed with a sleep disorder. In all cases, the percentage of participants with sleep problems increased with the number of chronic diseases.

\section{DISCUSSION}

Results from the present nationwide population-based study show for the first time in Luxembourg the prevalence of sleep patterns, with a focus on short and long sleep duration, as well as their association with multimorbidity. The prevalence of short sleep duration in Luxembourg is $5.13 \%$. Results are similar to those observed internationally, ${ }^{28}{ }^{30}$ although in countries such as Brazil the prevalence of short sleep duration was nearly 22\%, ${ }^{31}$ and in Portugal values of short sleep duration defined as $\leq 5$ hours reached up to $20 \%$ in $2015-$ $2016 .{ }^{32}$ However, in the present study, the age range from 25 to 64 years must be considered since it does not include adults over 65 years old who generally sleep 
Table 1 Chronic diseases/conditions, multimorbidity and sleep: European Health Examination Survey in Luxembourg $(n=1508)$

\section{Hypertension}

$\mathbf{N}(\%) /$ mean \pm SD

High cholesterol

250 (16.59)

Diabetes

458 (30.39)

Coronary heart disease or angina pectoris

$69(4.58)$

Myocardial infarction or chronic consequences of myocardial infarction

$26(1.73)$

Stroke or chronic consequences of stroke

$14(0.93)$

Stomach or duodenal ulcer

$11(0.73)$

Cirrhosis of the liver or other liver disease

$81(5.37)$

Urinary incontinence, problems in controlling the bladder

$46(3.05)$

Kidney problems

$74(4.91)$

$108(7.17)$

Chronic low back disorder or other chronic back defect

$489(32.47)$

Chronic neck disorder or other chronic neck defect

Rheumatoid arthritis

Arthrosis

$292(19.38)$

Osteoporosis

$44(2.92)$

Cancer

Severe headache such as migraine

Chronic anxiety

$98(6.50)$

Depression

No of chronic diseases

\begin{tabular}{lc}
0 & $405(27.00)$ \\
1 & $362(24.13)$ \\
$\geq 3$ & $733(49.00)$ \\
Sleep & $465(31.00)$ \\
\hline Diagnosis of sleep disorder & $122(8.21)$ \\
Sleepiness* & $118(7.89)$ \\
Have difficulties in sleeping the night through & $510(33.89)$ \\
Sleeping medication & $64(4.26)$ \\
Sleep duration & \\
\hline Total sleep duration $(n=1170)$ & $60(5.13 \%)$ \\
$<6$ hours/night & $1089(93.08 \%)$ \\
$6-9$ hours/night & $21(1.79 \%)$ \\
$>9$ hours/night & $6.95 \pm 0.97$ \\
Hours when you have to work the next day $(n=1152$-working) & $7.86 \pm 1.30$ \\
\hline Hours when you do not work the next day $(n=1501)$ & \\
\hline
\end{tabular}

Missing values ranged from 2 to 13 observations.

${ }^{*}$ Measured with Epworth Sleepiness Scale.

less hours. This means that the overall prevalence of the Luxembourg population sleeping less than the recommended hours is likely to be higher, when including older adults as well.

Multimorbidity is highly prevalent in Luxembourg, especially when taking into account the fact that the study population was up to 65 years, which represents a relatively young population, as multimorbidity prevalence naturally increases with age. ${ }^{22}$ Nearly half of participants had two or more chronic diseases and $31 \%$ had three or more chronic diseases/conditions.

In our study, we observed that short sleep duration was significantly associated with the number of chronic conditions independently of socioeconomic, 
Table 2 Participant characteristics by chronic conditions/diseases: European Health Examination Survey in Luxembourg $(n=1508)$

\begin{tabular}{lllll} 
Chronic conditions/diseases & & & \\
\hline 0 & 1 & 2 & $\geq 3$ & P value* $^{*}$
\end{tabular}

\begin{tabular}{|c|c|c|c|c|c|}
\hline \multicolumn{6}{|l|}{ Sex } \\
\hline Male & 199 (27.72) & 199 (27.72) & 143 (19.92) & 177 (24.65) & $<0.001$ \\
\hline Female & $206(26.34)$ & $163(20.84)$ & $125(15.98)$ & $288(36.83)$ & \\
\hline \multicolumn{6}{|l|}{ Age } \\
\hline $25-34$ & 130 (43.62) & $86(28.86)$ & 48 (16.11) & 34 (11.41) & $<0.001$ \\
\hline $35-44$ & $156(34.29)$ & $119(26.15)$ & 69 (15.16) & $111(24.40)$ & \\
\hline $45-54$ & $83(18.16)$ & $111(24.29)$ & $98(21.44)$ & $165(36.11)$ & \\
\hline $55-64$ & $36(12.41)$ & $46(15.86)$ & $53(18.28)$ & $155(53.45)$ & \\
\hline \multicolumn{6}{|l|}{ Immigration } \\
\hline Luxembourg & $184(23.44)$ & $197(25.10)$ & 144 (18.34) & 260 (33.12) & $<0.001$ \\
\hline Portugal & $52(23.85)$ & $42(19.27)$ & $45(20.64)$ & $79(36.24)$ & \\
\hline Other & $169(34.00)$ & $123(24.75)$ & 79 (15.90) & $126(25.35)$ & \\
\hline \multicolumn{6}{|l|}{ Education } \\
\hline Primary & $68(18.38)$ & $75(20.27)$ & $64(17.30)$ & $163(44.05)$ & $<0.001$ \\
\hline Secondary & 133 (23.05) & 142 (24.61) & 106 (18.37) & 196 (33.97) & \\
\hline Tertiary & $203(37.04)$ & $145(26.46)$ & $97(17.70)$ & $103(18.80)$ & \\
\hline \multicolumn{6}{|l|}{ Job } \\
\hline Not working & $58(16.67)$ & $56(16.09)$ & $58(16.67)$ & $176(50.57)$ & $<0.001$ \\
\hline Managers/professionals & 168 (35.59) & $138(29.24)$ & $73(15.47)$ & $93(19.70)$ & \\
\hline Technicians/clerical/service occupation & $119(29.38)$ & $89(21.98)$ & $76(18.77)$ & $121(29.88)$ & \\
\hline Skilled/unskilled workers & $60(21.90)$ & $79(28.83)$ & $61(22.26)$ & $74(27.01)$ & \\
\hline \multicolumn{6}{|l|}{ Smoking } \\
\hline Never & $239(29.25)$ & $209(25.58)$ & $145(17.75)$ & $224(27.42)$ & 0.026 \\
\hline Current & $90(26.01)$ & $75(21.68)$ & $63(18.21)$ & $118(34.10)$ & \\
\hline Ex-smoker & 74 (22.09) & $78(23.28)$ & $60(17.91)$ & $123(36.72)$ & \\
\hline \multicolumn{6}{|l|}{ Alcohol } \\
\hline Never & $30(27.78)$ & $21(19.44)$ & $20(18.52)$ & $37(34.26)$ & 0.055 \\
\hline Drinkers & $365(27.53)$ & $328(24.74)$ & $234(17.65)$ & $399(30.09)$ & \\
\hline Ex-drinkers & $8(12.50)$ & $13(20.31)$ & $14(21.88)$ & $29(45.31)$ & \\
\hline \multicolumn{6}{|l|}{ Fruit and vegetable consumption } \\
\hline$<1$ portion/day & $126(27.39)$ & $112(24.35)$ & $87(18.91)$ & $135(29.35)$ & 0.597 \\
\hline 1-4 portions/day & $223(27.81)$ & $183(22.82)$ & $142(17.71)$ & $254(31.67)$ & \\
\hline$\geq 5$ portions/day & 55 (23.31) & 66 (27.97) & $39(16.53)$ & 76 (32.20) & \\
\hline \multicolumn{6}{|l|}{ Physical activity } \\
\hline Never & $130(21.35)$ & $133(21.84)$ & $125(20.53)$ & 221 (36.29) & $<0.001$ \\
\hline$\leq 3$ hours/week & $151(29.84)$ & 130 (25.69) & 77 (15.22) & $148(29.25)$ & \\
\hline$>3$ hours/week & $121(31.84)$ & 98 (25.79) & 65 (17.11) & $96(25.26)$ & \\
\hline BMI & $25.27 \pm 4.06$ & $26.04 \pm 4.89$ & $26.66 \pm 4.96$ & $28.07 \pm 5.56$ & $<0.001$ \\
\hline$<25$ & $212(33.02)$ & 169 (26.32) & $112(17.45)$ & 149 (23.21) & $<0.001$ \\
\hline $25-30$ & $152(27.39)$ & $131(23.60)$ & $100(18.02)$ & 172 (30.99) & \\
\hline$\geq 30$ & 41 (13.62) & $61(20.27)$ & 55 (18.27) & $144(47.84)$ & \\
\hline
\end{tabular}

Values are numbers (\%) for categorical variables and means \pm SD for continuous variables.

${ }^{*} \chi^{2}$ test for categorical variables, $t$-test for continuous variables. Missing values ranged from 8 to 13 observations.

$\mathrm{BMI}$, body mass index. 
Table 3 Participant's characteristics by sleep duration: European Health Examination Survey in Luxembourg

\begin{tabular}{|c|c|c|c|c|}
\hline & \multicolumn{4}{|c|}{ Sleep duration $(n=1170)$} \\
\hline & $<6$ hours/night & 6-9 hours/night & $>9$ hours/night & P value* \\
\hline \multicolumn{5}{|l|}{ Sex } \\
\hline Men & $35(5.85)$ & 559 (93.48) & $4(0.67)$ & 0.007 \\
\hline Women & $25(4.37)$ & $530(92.66)$ & $17(2.97)$ & \\
\hline Age & $44.88 \pm 8.53$ & $43.00 \pm 9.04$ & $42.11 \pm 10.43$ & 0.26 \\
\hline 25-34 & 8 (3.03) & $251(95.08)$ & $5(1.89)$ & 0.50 \\
\hline $35-44$ & $22(5.53)$ & 367 (92.21) & $9(2.26)$ & \\
\hline $45-54$ & $22(5.70)$ & 360 (93.26) & $4(1.04)$ & \\
\hline $55-64$ & $8(6.56)$ & $111(90.98)$ & $3(2.46)$ & \\
\hline \multicolumn{5}{|l|}{ Immigration } \\
\hline Luxembourg & $23(3.75)$ & 581 (94.78) & $9(1.47)$ & 0.02 \\
\hline Portugal & $17(10.00)$ & $151(88.82)$ & $2(1.18)$ & \\
\hline Other & $20(5.17)$ & 357 (92.25) & $10(2.58)$ & \\
\hline \multicolumn{5}{|l|}{ Education } \\
\hline Primary & $21(8.90)$ & $212(89.83)$ & $3(1.27)$ & 0.007 \\
\hline Secondary & $25(5.81)$ & 395 (91.86) & $10(2.33)$ & \\
\hline Tertiary & $14(2.80)$ & 478 (95.60) & $8(1.60)$ & \\
\hline \multicolumn{5}{|l|}{ Job } \\
\hline Not working & $0(0.00)$ & 19 (95.00) & $1(5.00)$ & 0.05 \\
\hline Managers/professionals & $15(3.18)$ & $450(95.34)$ & $7(1.48)$ & \\
\hline Technicians/clerical/service occupation & $23(5.64)$ & $376(92.16)$ & $9(2.21)$ & \\
\hline Skilled/unskilled workers & $22(8.15)$ & $244(90.37)$ & $4(1.48)$ & \\
\hline \multicolumn{5}{|l|}{ Smoking } \\
\hline Never & $32(4.79)$ & 625 (93.56) & $11(1.65)$ & 0.84 \\
\hline Current & $15(5.60)$ & 249 (92.91) & $4(1.49)$ & \\
\hline Ex-smoker & $13(5.58)$ & $214(91.85)$ & $6(2.58)$ & \\
\hline \multicolumn{5}{|l|}{ Alcohol } \\
\hline Never & $4(5.63)$ & $63(88.73)$ & $4(5.63)$ & 0.03 \\
\hline Drinkers & $52(4.89)$ & $996(93.61)$ & $16(1.50)$ & \\
\hline Ex-drinkers & $4(11.43)$ & $30(85.71)$ & $1(2.86)$ & \\
\hline \multicolumn{5}{|l|}{ Fruit and vegetable consumption } \\
\hline$<1$ portion/day & $19(5.04)$ & 351 (93.10) & $7(1.86)$ & 0.72 \\
\hline 1-4 portions/day & $36(5.76)$ & $578(92.48)$ & $11(1.76)$ & \\
\hline$\geq 5$ portions/day & $5(2.99)$ & $159(95.21)$ & $3(1.80)$ & \\
\hline \multicolumn{5}{|l|}{ Physical activity } \\
\hline Never & $36(7.81)$ & $413(89.59)$ & $12(2.60)$ & 0.003 \\
\hline$\leq 3$ hours/week & $12(2.86)$ & 401 (95.48) & 7 (1.67) & \\
\hline$>3$ hours/week & $12(4.15)$ & $275(95.16)$ & $2(0.69)$ & \\
\hline BMI & $27.57 \pm 4.80$ & $26.36 \pm 4.87$ & $25.27 \pm 6.53$ & 0.10 \\
\hline$<25$ & $16(3.16)$ & 477 (94.27) & $13(2.57)$ & 0.003 \\
\hline $25-30$ & $30(6.80)$ & 409 (92.74) & $2(0.45)$ & \\
\hline$\geq 30$ & $14(6.31)$ & 202 (90.99) & $6(2.70)$ & \\
\hline
\end{tabular}

Values are numbers (\%) for categorical variables and means \pm SD for continuous variables. ${ }^{*} \chi^{2}$ test or Fisher's exact test for categorical variables, ANOVA for continuous variables. $\mathrm{BMI}$, body mass index. 
Table 4 Results of multinomial logistic regression measuring the association between sleep duration and chronic conditions in models adjusted for participants sociodemographic characteristics, behavioural risk factors and measures of sleep disorders and sleep quality: European Health Examination Survey in Luxembourg $(n=1170)$

\begin{tabular}{|c|c|c|c|c|}
\hline & \multicolumn{4}{|l|}{ Sleep duration } \\
\hline & \multicolumn{2}{|l|}{ Short (<6 hours) } & \multicolumn{2}{|l|}{ Long (>9 hours) } \\
\hline & OR (95\% Cl) & AOR $(95 \% \mathrm{Cl})$ & OR $(95 \% \mathrm{Cl})$ & AOR (95\% Cl) \\
\hline 0 & 1.00 & 1.00 & 1.00 & 1.00 \\
\hline 1 & 4.55 (1.49 to 13.88$)$ & 4.65 (1.48 to 14.51$)$ & 2.94 (0.93 to 9.19$)$ & 2.66 (0.80 to 8.85$)$ \\
\hline \multicolumn{5}{|l|}{ Immigration } \\
\hline Luxembourg & & 1.00 & & 1.00 \\
\hline Portugal & & $1.66(0.71$ to 3.89$)$ & & $0.86(0.14$ to 5.08$)$ \\
\hline Other & & 1.96 (1.00 to 3.82$)$ & & 1.80 (0.61 to 5.31$)$ \\
\hline Age & & 0.99 (0.95 to 1.02$)$ & & 0.98 (0.93 to 1.04$)$ \\
\hline \multicolumn{5}{|l|}{ Education } \\
\hline Primary & & 1.00 & & 1.00 \\
\hline Secondary & & 0.77 (0.35 to 1.71$)$ & & 1.79 (0.36 to 8.85$)$ \\
\hline Tertiary & & $0.36(0.12$ to 1.11$)$ & & 1.07 (0.14 to 7.85$)$ \\
\hline \multicolumn{5}{|l|}{ Job status } \\
\hline \multicolumn{5}{|l|}{ Unemployed } \\
\hline Managers/professionals & & 1.00 & & 1.00 \\
\hline Technicians/clerical/service occupation & & $1.17(0.50$ to 2.68$)$ & & $1.47(0.40$ to 5.39$)$ \\
\hline Normal & & 1.00 & & 1.00 \\
\hline Overweight & & 1.49 (0.74 to 2.98$)$ & & 0.29 (0.06 to 1.39$)$ \\
\hline Obese & & 0.94 (0.40 to 2.16$)$ & & 1.25 (0.35 to 4.40$)$ \\
\hline \multicolumn{5}{|l|}{ Smoking } \\
\hline Never & & 1.00 & & 1.00 \\
\hline Current & & $0.92(0.46$ to 1.84$)$ & & $1.13(0.30$ to 4.15$)$ \\
\hline Ex-smokers & & $0.88(0.42$ to 1.86$)$ & & $3.30(0.98$ to 11.00$)$ \\
\hline \multicolumn{5}{|l|}{ Alcohol consumption } \\
\hline Never & & 1.00 & & 1.00 \\
\hline Drink & & 2.21 (0.39 to 12.48$)$ & & 0.60 (0.05 to 7.13$)$ \\
\hline Ex-drinker & & $1.14(0.31$ to 4.10$)$ & & 0.32 (0.07 to 1.44$)$ \\
\hline Sleeping medication & & 1.89 (0.56 to 6.35$)$ & & NA \\
\hline Sleep disorder diagnosis & & 1.39 (0.55 to 3.49$)$ & & NA \\
\hline Difficulties in sleeping the night & & $2.12(1.14$ to 3.92$)$ & & $1.34(0.45$ to 3.90$)$ \\
\hline Sleepiness & & 3.37 (1.57 to 7.21$)$ & & 1.09 (0.20 to 5.77$)$ \\
\hline
\end{tabular}

AOR, adjusted OR; BMI, body mass index; NA, not available. 
behavioural characteristics and sleep disorders. Our results are in line with those from other studies that observed an association between sleep and number of chronic diseases, although previous studies have been usually performed in populations of older adults (eg, over 50 years old). ${ }^{1933}$ As observed by Koyanagi et al, sleep problems increase with the number of diseases in both low-income and high-income countries independent of their economic development. ${ }^{19}$ These associations could explain the observed relationship between sleep duration (under the recommended 7 hours) and poor sleep quality with mortality, even among adults younger than 65 years old. ${ }^{18}$ It is not clear if sleep problems are a consequence of chronic diseases (eg, conditions affecting sleep) or part of the cause (sleep predisposes the individual to more diseases or exacerbates the symptoms), although it is plausible that both sleep problems and chronic diseases are linked by a bidirectional association. ${ }^{34}$ In terms of potential mechanisms to corroborate the biological plausibility of the link between short sleep duration and multimorbidity, reduced sleep duration has been associated with a number of chronic conditions, including cardiometabolic and neurodegenerative disease, cancer, musculoskeletal disorders and mental problems. ${ }^{15}{ }^{16}$ Pain caused by certain chronic diseases as well as the medications/treatments used and mood disorders (eg, anxiety, depression) could have an impact on sleep. ${ }^{35}$ In turn, sleep disturbances could worsen the health status. Experimental evidence corroborates the plausibility of deleterious effects of lack of sleep on endocrine, immune, neurovegetative and inflammatory pathways. ${ }^{1-3}$ Sustained short sleep duration could be related to chronic conditions through its impact on the circadian rhythm and its association with hormonal (eg, insulin resistance and decreased leptin) and autonomic nervous system changes (increased activity of the sympathetic nervous system).$^{36}$ Although both reduced sleep duration and the number of chronic diseases increase with age, and are more prevalent in older adults, our study shows that the prevalence is also high in adults under 65 and the association begins much earlier. It is therefore necessary to detect these problems earlier in order to improve individual health and general wellbeing and reduce mortality, particularly in the context of ageing populations burdened by the accumulation of multiple chronic conditions over time. In our study, we also observed that short sleep duration was associated with immigration status. The relationship between immigration status and sleep patterns remains unclear, possibly related to stress linked to the migratory process, cultural adaptation or working conditions in the host country. ${ }^{37} 38$ In our study, Portuguese immigrants were more likely to sleep less than 6 hours per night during workdays and less than 7 hours during non-working days. Portuguese are the largest immigrant community in Luxembourg, accounting for $16 \%$ of the $46 \%$ immigrant population living in Luxembourg. Compared with
Luxembourgish natives, Portuguese immigrants have a lower socioeconomic status ${ }^{39}$ (including income, education and employment) which could partly explain why they have a greater likelihood of being short sleepers. However, after calculating the weight average for sleep hours and adjusting for sleep disorders, the association with short sleep duration disappeared.

In our study, long sleep duration was more common in women. This was in line with other studies showing that men usually sleep less hours, although women reported having more sleep problems. ${ }^{40}$ However, this relationship is complex and could depend on family composition (eg, single parents have shorter sleep duration, particularly women). ${ }^{41}$

In addition, short sleep duration often cluster with other behavioural risk factors such as cigarette smoking, heavy drinking and physical inactivity, which may in turn increase the risk of chronic disease. However, in our study, we only observed an association between physical activity and short sleep duration, with no association observed between short sleep duration and smoking or alcohol consumption. Regular physical activity would reduce the likelihood of short and/or long sleep duration and maintain an optimal duration. Studies have observed an association between physical activity and sleep, improving quality of sleep, sleep efficiency and total sleep time. ${ }^{12} 42$

Limitations of the present study include the subjective measure of sleep duration (self-reported number of hours of sleep) instead of an objective measure (eg, actigraphy, polysomnography). However, in the absence of an objective measure, there is a moderate correlation between objective and subjective measurements, a correlation that is high during weekdays possibly due to routines, ${ }^{43}$ but may be attenuated based on certain individual characteristics (eg, presence of conditions such as depression, sociodemographic characteristics) ${ }^{44}$ Other limitations include the fact that we did not include other sleep problems such as insomnia or sleep apnoea nor environmental factors such as noise, traffic or commuting, all of which could affect sleep duration. In addition, multimorbidity was also self-reported based on a restricted list of diseases in the questionnaire; therefore, participants may have not reported additional conditions, which may produce a possible underestimation of multimorbidity prevalence. Information on non-responders was not available, and despite being a representative sample of the Luxembourg population (in terms of age, sex and district), we could not determine the possibility of a non-response bias. In our study, we only included the number of sleep hours during the night, without including nap times. Moreover, we did not have information on the number of days that participants were working and assumed that most were working 5 days per week. Finally, it should be noted that the study design (cross-sectional) does not allow to ascertain a causal link between sleep and multimorbidity; in addition, the low participation rate may affect the generalisability of our results.

This is the first study in Luxembourg on the prevalence of sleep patterns, with a focus on short and long sleep 
duration, and their relationship with multimorbidity. Short sleep duration, having difficulties in sleeping the night through, sleep disorders and sleeping medication represent a neglected public health problem, especially when associated with a number of chronic conditions and diseases, thus producing a negative impact on the well-being and general health status of the population. Sleep hygiene should be considered as an additional important health behaviour along with diet, smoking and physical activity, both in clinical and public health practice. As both sleep problems and multimorbidity are highly prevalent in Luxembourg, health promotion programmes should be developed to improve and promote healthy lifestyles among the general population to improve sleep habits as well as decrease multimorbidity.

\section{Author affiliations}

${ }^{1}$ Epidemiology and Public Health Research Unit, Department of Population Health, Luxembourg Institute of Health, Strassen, Luxembourg

${ }^{2}$ Department of Family Medicine, Care and Public Health Research Institute, Maastricht University, Maastricht, The Netherlands

${ }^{3}$ Competence Center in Methodology and Statistics, Department of Population Health, Luxembourg Institute of Health, Strassen, Luxembourg

${ }^{4}$ Department of Epidemiology and Biostatistics, Schulich School of Medicine and Dentistry, Western University, London, Ontario, Canada

${ }^{5}$ Department of Family Medicine, Schulich School of Medicine and Dentistry, Western University, London, Ontario, Canada

Acknowledgements We are grateful to the population of Luxembourg and to all the EHES-LUX team who have contributed to this study. We would like to thank Kuemmerle A, Barre J, Dincau M, Delagardelle C, Michel G, Schlesser M, Mormont D, Chioti A, Gantenbein M, Lieunard C, Columeau A, Kiemen M, Weis J, Ambrozet G, Billy A, Larcelet M, Marcic D, Gauthier C and Viau-Courville M for their valuable contributions.

Contributors MR-C and SS conceptualised and designed the study. MR-C and VB performed the statistical analysis. MR-C, SS and TTM interpreted the data. MR-C drafted the article. SS supervised the study. All authors participated in the revision of the article. All authors contributed to and have approved the final manuscript.

Funding The study was funded by the Directorate and Ministry of Health and the Luxembourg Institute of Health.

Competing interests None declared.

Patient consent for publication Obtained.

Ethics approval The study national research ethics committee (Comité national d'éthique de Recherche-CNER) approved the study and it was notified to the Luxemburgish National Commission for Data Protection.

Provenance and peer review Not commissioned; externally peer reviewed.

Data availability statement Data are available on reasonable request.

Open access This is an open access article distributed in accordance with the Creative Commons Attribution Non Commercial (CC BY-NC 4.0) license, which permits others to distribute, remix, adapt, build upon this work non-commercially, and license their derivative works on different terms, provided the original work is properly cited, appropriate credit is given, any changes made indicated, and the use is non-commercial. See: http://creativecommons.org/licenses/by-nc/4.0/.

\section{REFERENCES}

1. Ferrie JE, Kivimäki M, Akbaraly TN, et al. Associations between change in sleep duration and inflammation: findings on C-reactive protein and interleukin 6 in the Whitehall II study. Am J Epidemiol 2013;178:956-61.

2. Ferrie JE, Shipley MJ, Akbaraly TN, et al. Change in sleep duration and cognitive function: findings from the Whitehall II study. Sleep 2011;34:565-73.
3. St-Onge M-P. The role of sleep duration in the regulation of energy balance: effects on energy intakes and expenditure. J Clin Sleep Med 2013;9.

4. Watson NF, Badr MS, Belenky G, et al. Recommended amount of sleep for a healthy adult: a joint consensus statement of the American Academy of Sleep Medicine and Sleep Research Society. Sleep 2015;38:843-4.

5. Centers for Disease Control and Prevention CDC 24/7: Saving lives. Protecting People 1600 Clifton Road Atlanta, GA 30329-4027 USA [updated 5 Jun 2017]. National Center for Chronic Disease Prevention and Health Promotion, Division of Population Health. Available: https://www.cdc.gov/sleep/about_us.html

6. Buysse DJ. Sleep health: can we define it? Does it matter? Sleep 2014;37:9-17.

7. Ford ES, Cunningham TJ, Croft JB. Trends in self-reported sleep duration among US adults from 1985 to 2012. Sleep 2015;38:829-32.

8. Stranges S, Dorn JM, Shipley MJ, et al. Correlates of short and long sleep duration: a cross-cultural comparison between the United Kingdom and the United States: the Whitehall II study and the Western New York Health Study. Am J Epidemiol 2008;168:1353-64.

9. Grandner MA, Williams NJ, Knutson KL, et al. Race/ethnicity, and socioeconomic position. Sleep Med 2016;18:7-18.

10. Yoon H-S, Yang JJ, Song M, et al. Correlates of self-reported sleep duration in middle-aged and elderly Koreans: from the Health Examinees Study. PLoS One 2015;10:e0123510.

11. Stringhini S, Haba-Rubio J, Marques-Vidal P, et al. Association of socioeconomic status with sleep disturbances in the Swiss population-based CoLaus study. Sleep Med 2015;16:469-76.

12. Gubelmann C, Heinzer R, Haba-Rubio J, et al. Physical activity is associated with higher sleep efficiency in the general population: the CoLaus study. Sleep 2018;41. 10.1093/sleep/zsy070. [Epub ahead of print: 01 Jul 2018].

13. Campanini MZ, Guallar-Castillón P, Rodríguez-Artalejo F, et al. Mediterranean diet and changes in sleep duration and indicators of sleep quality in older adults. Sleep 2017;40.

14. Dashti HS, Scheer FA, Jacques PF, et al. Short sleep duration and dietary intake: epidemiologic evidence, mechanisms, and health implications. Adv Nutr 2015;6:648-59.

15. Alcántara C, Biggs ML, Davidson KW, et al. Sleep disturbances and depression in the multi-ethnic study of atherosclerosis. Sleep 2016;39:915-25.

16. Rangaraj VR, Knutson KL. Association between sleep deficiency and cardiometabolic disease: implications for health disparities. Sleep Med 2016;18:19-35.

17. St-Onge M-P, Grandner MA, Brown D, et al. Sleep duration and quality: impact on lifestyle behaviors and cardiometabolic health: a scientific statement from the American Heart Association. Circulation 2016;134:e367-86.

18. Akerstedt T, Ghilotti F, Grotta A, et al. Mortality and the influence of age. Eur J Epidemiol 2017;32:881-91.

19. Koyanagi A, Garin N, Olaya B, et al. Chronic conditions and sleep problems among adults aged 50 years or over in nine countries: a multi-country study. PLoS One 2014;9:e114742.

20. Wang S, Li B, Wu Y, et al. Relationship of sleep duration with sociodemographic characteristics, lifestyle, mental health, and chronic diseases in a large Chinese adult population. J Clin Sleep Med 2017;13:377-84.

21. van den Akker M, Buntinx F, Knottnerus JA. Comorbidity or multimorbidity: what's in a name? A review of literature. Eur $J$ Gen Pract 1996;2:65-70.

22. Xu X, Mishra GD, Jones M. Evidence on multimorbidity from definition to intervention: an overview of systematic reviews. Ageing Res Rev 2017;37:53-68.

23. Afshar S, Roderick PJ, Kowal P, et al. Multimorbidity and the inequalities of global ageing: a cross-sectional study of 28 countries using the world health surveys. BMC Public Health 2015;15:776.

24. Barnett K, Mercer SW, Norbury M, et al. Epidemiology of multimorbidity and implications for health care, research, and medical education: a cross-sectional study. The Lancet 2012;380:37-43.

25. Ruiz-Castell M, Kandala N-B, Kuemmerle A, et al. Hypertension burden in Luxembourg: individual risk factors and geographic variations, 2013 to 2015 European Health Examination Survey. Medicine 2016;95:e4758.

26. Bakour C, Schwartz S, O'Rourke K, et al. Sleep duration trajectories and systemic inflammation in young adults: results from the Nationa Longitudinal Study of Adolescent to Adult Health (Add Health). Sleep 2017;40. 10.1093/sleep/zsx156. [Epub ahead of print: $01 \mathrm{Nov}$ 2017]. 
27. Watanabe M, Kikuchi H, Tanaka K, et al. Association of short sleep duration with weight gain and obesity at 1-year follow-up: a largescale prospective study. Sleep 2010;33:161-7.

28. Lakerveld J, Mackenbach JD, Horvath E, et al. The relation between sleep duration and sedentary behaviours in European adults. Obes Rev 2016;17(Suppl 1):62-7.

29. Johns MW. A new method for measuring daytime sleepiness: the Epworth Sleepiness Scale. Sleep 1991;14:540-5.

30. Kleiser C, Wawro N, Stelmach-Mardas M, et al. Are sleep duration, midpoint of sleep and sleep quality associated with dietary intake among Bavarian adults? Eur J Clin Nutr 2017;71:631-7.

31. Lima MG, Bergamo Francisco PMS, de Azevedo Barros MB. Sleep duration pattern and chronic diseases in Brazilian adults (ISACAMP, 2008/09). Sleep Med 2012;13:139-44.

32. Reis C, Dias S, Rodrigues AM, et al. Sleep duration, lifestyles and chronic diseases: a cross-sectional population-based study. Sleep Sci 2018;11:217-30.

33. Wang $\mathrm{Y}-\mathrm{M}$, Song $\mathrm{M}$, Wang $\mathrm{R}$, et al. Insomnia and multimorbidity in the community elderly in China. J Clin Sleep Med 2017;13:591-7.

34. Marshall NS, Stranges S. Are sleep difficulties the "canary in the coalmine" for aortic calcification in women? Sleep Med 2013;14:389-90.

35. Onen S-H, Onen F. Chronic medical conditions and sleep in the older adult. Sleep Med Clin 2018;13:71-9.

36. Gangwisch JE. Epidemiological evidence for the links between sleep, circadian rhythms and metabolism. Obesity Reviews 2009;10:37-45.
37. Grandner MA, Petrov MER, Rattanaumpawan P, et al. Sleep symptoms, race/ethnicity, and socioeconomic position. J Clin Sleep Med 2013;9:897-905.

38. Jackson CL, Hu FB, Redline S, et al. Racial/ethnic disparities in short sleep duration by occupation: the contribution of immigrant status. Soc Sci Med 2014;118:71-9.

39. Vincent H, Noel PAM, Philippe VK. Measuring and accounting for the deprivation gap of Portuguese immigrants in Luxembourg. LISER, 2012.

40. Polo-Kantola P, Laine A, Kronholm E, et al. Gender differences in actual and preferred nocturnal sleep duration among Finnish employed population. Maturitas 2016;94:77-83.

41. Nugent CN, Black LI, Duration S. Quality of sleep, and use of sleep medication, by sex and family type, 2013-2014. NCHS data brief 2016;230:1-8.

42. Kredlow MA, Capozzoli MC, Hearon BA, et al. The effects of physical activity on sleep: a meta-analytic review. J Behav Med 2015;38:427-49.

43. Cespedes EM, Hu FB, Redline S, et al. Comparison of selfreported sleep duration with actigraphy: results from the Hispanic Community Health Study/Study of Latinos Sueño Ancillary Study. Am J Epidemiol 2016;183:561-73.

44. Matthews KA, Patel SR, Pantesco EJ, et al. Similarities and differences in estimates of sleep duration by polysomnography, actigraphy, diary, and self-reported habitual sleep in a community sample. Sleep Health 2018;4:96-103. 